\title{
Práticas alimentares no primeiro ano de vida: representações sociais de mães adolescentes
}

\author{
Eating habits in the first year of life: social representations of young mothers
}

Los hábitos de alimentación en el primer año de vida: las representaciones sociales de las madres adolescentes

\section{Ana Paula Esmeraldo Lima', Marly Javorski", Rosemary de Jesus Machado Amorim"'I, Sheyla Costa de Oliveira", Maria Gorete Lucena de Vasconcelos ${ }^{1}$}

\author{
' Universidade Federal de Pernambuco, Departamento de Enfermagem, \\ Programa de Pós-Graduação em Saúde da Criança e do Adolescente. Recife-PE, Brasil. \\ "Universidade Federal de Pernambuco, Departamento de Enfermagem. Recife-PE, Brasil. \\ "I' Universidade Federal de Pernambuco, Departamento Materno-infantil, \\ Programa de Pós-Graduação em Saúde da Criança e do Adolescente. Recife-PE, Brasil.
}

Submissão: 27-06-2013 Aprovação: 03-11-2014

\section{RESUMO}

Trata-se de pesquisa qualitativa exploratória, que buscou analisar as representações sociais de mães adolescentes sobre as práticas alimentares do filho no primeiro ano de vida. Teve como sujeitos 10 mães adolescentes, cujos filhos encontravam-se na faixa etária de sete a doze meses de vida. Os dados foram coletados por meio de entrevista semi-estruturada, além da utilização de material visual. A análise seguiu a técnica de análise de conteúdo, apoiando-se no referencial da Teoria das Representações Sociais. Dessa análise, emergiram quatro temas: conflito do amamentar versus consagração do mingau; estabelecendo a alimentação complementar do filho; discurso cristalizado: "danoninho vale mais que um bifinho"; a (in)definição dos hábitos alimentares maternos: implicações para a alimentação infantil. As representações que conduzem as práticas maternas na escolha, preparo e oferta dos alimentos seguem uma lógica particular, onde as adolescentes reinterpretam os discursos técnicos nos termos da sua cultura.

Descritores: Adolescente; Aleitamento Materno; Nutrição do Lactente; Hábitos Alimentares; Educação em Saúde.

\section{ABSTRACT}

This is qualitative research that investigates the social representations of adolescent mothers on child eating habits in the first year of life. Its subjects were 10 adolescent mothers, whose children were aged seven to twelve months. Data were collected through semi-structured interview, besides the use of visual material. The analysis followed the technique of content analysis, relying on the framework of Social Representations Theory. That analysis revealed four themes: the conflict of breastfeeding versus consecration of porridge; establishing complementary feeding of the child; crystallized speech: "yogurt is better than a little steak"; the (un)definition of maternal eating habits: implications for infant feeding. The representations that drive maternal practices in selecting, preparing and offering food follow a particular logic, where adolescents reinterpret technical speeches in terms of their culture.

Key words: Adolescent; Breastfeeding; Infant Nutrition; Food Habits; Health Education.

\section{RESUMEN}

Esta es una investigación cualitativa que investiga las representaciones sociales de madres adolescentes en las prácticas de alimentación infantil en el primer año de vida. El estudio incluyó a 10 madres adolescentes cuyos hijos tenían entre siete a doce meses. Los datos fueron obtenidos mediante entrevista semiestructurada, además de la utilización de material visual. El análisis se realizó por la técnica de análisis de contenido, basándose en el marco de la teoría de las representaciones sociales. Ese análisis revelo cuatro temas: el conflicto de la lactancia materna frente a la consagración de la papilla; el establecimiento de alimentación complementaria del niño; discurso cristalizado "el yogur es mejor que un filete"; la dieta materna sin definición: implicaciones para la alimentación infantil. Las representaciones que impulsan prácticas maternas en la selección, preparación y oferta de alimentos siguen una lógica particular, donde las adolescentes reinterpretan intervenciones técnicas en términos de su cultura. Palabras clave: Adolescente; Lactancia Materna; Nutrición del Lactante; Hábitos Alimenticios; Educación en Salud.

* Trabalho baseado na dissertação de mestrado: Lima APE. Práticas alimentares no primeiro ano de vida na percepção de mães adolescentes. Recife, 2011 Dissertação (Mestrado). Universidade Federal de Pernambuco. Programa de Pós-Graduação em Saúde da Criança e do Adolescente. 


\section{INTRODUÇÃO}

A alimentação infantil está associada ao perfil de saúde e nutrição nos primeiros anos de vida. O aleitamento materno exclusivo durante os seis primeiros meses de vida e complementado, com alimentação oportuna e adequada, até os dois anos de idade ou mais é o recomendado pela Organização Mundial de Saúde para as crianças de todo o mundo(1).

As práticas alimentares estabelecidas nos primeiros anos de vida irão repercutir na adolescência e na idade adulta. A alimentação não é mero ato biológico, mas se constitui uma prática socialmente elaborada, relacionada à cultura e às relações familiares. O comportamento alimentar da criança é influenciado pelo ambiente familiar, representado pela figura materna, a qual desenvolve papel fundamental em relação ao cuidado com o filho. A maternidade na adolescência, contudo, configura-se como fator de risco para a ocorrência de agravos nutricionais no concepto ${ }^{(2-3)}$.

As ideias e crenças alimentares estão enraizadas nos grupos sociais, podendo ser compartilhadas pelas adolescentes que deles fazem parte. As representações que daí se desenvolvem são, portanto, fundadas no contexto social em que o indivíduo está inserido e orientam uma prática, sendo possível supor que a mãe adolescente estabelece de forma inapropriada a alimentação de seu filho, a partir do que é compartilhado como alimentação adequada pelo seu grupo ${ }^{(4)}$. Todavia, a mãe adolescente não é refém desta representação e como sujeito pode, a partir de novas vivências (orientações dos profissionais de saúde), reelaborar suas representações acerca da alimentação infantil.

Valer-se da Educação em Saúde é, portanto, fundamental, considerando-a como um instrumento de transformação social, de reformulação de hábitos e aceitação de novos saberes. Desvelar as representações sociais que estão conduzindo a prática das mães adolescentes no estabelecimento da alimentação de seus filhos pode contribuir para uma abordagem educativa mais eficaz à jovem mãe, fator preponderante para a proteção e promoção da saúde da criança e também da mãe adolescente enquanto ser em desenvolvimento. O objetivo deste estudo foi analisar as representações sociais das práticas alimentares da criança no primeiro ano de vida na perspectiva de mães adolescentes.

\section{MÉTODO}

Tratou-se de estudo descritivo e exploratório, construído a partir do método qualitativo ${ }^{(5)}$. A investigação foi desenvolvida em duas comunidades do bairro Ibura, em Recife, Pernambuco, assistidas pela Estratégia Saúde da Família. Esse bairro é um dos mais populosos da cidade, predominantemente de famílias de baixo nível socioeconômico, considerado ruim quanto aos determinantes da situação de saúde da mulher e da criança(6).

Participaram da pesquisa 10 mães adolescentes, com filhos na faixa etária de sete a doze meses de vida, exclusive. Foram excluídas as mães que não eram as principais responsáveis pela alimentação da criança (considerando-se a escolha, preparo e oferta do alimento) e aquelas cujos filhos foram prematuros. A quantidade de entrevistadas não visou à representatividade estatística, mas sim o critério de saturação teórica( ${ }^{(5)}$.

A identificação de um grupo de adolescentes-mães foi realizada mediante informação da Unidade de Saúde da Família. Realizou-se o contato prévio, no domicílio, onde as adolescentes foram convidadas a participar do estudo. $\mathrm{O}$ trabalho de campo transcorreu de março a maio de 2010, utilizando-se a entrevista semiestruturada, guiada por duas questões norteadoras: como foi sua vivência na alimentação do seu filho, desde o dia em que ele nasceu? Qual a sua opinião sobre a alimentação que oferece para seu filho hoje? As entrevistas, realizadas individualmente no domicílio das participantes, foram gravadas e, posteriormente, transcritas na íntegra.

O uso de material visual foi adotado como estratégia de triangulação metodológica ${ }^{(5)}$, permitindo enriquecer e complementar o conhecimento sobre o tema, além de tentar superar as possíveis limitações do método individual. Para tanto, ao término da entrevista, eram exibidas figuras de alimentos (em tamanho $10 \times 15 \mathrm{~cm}$, cada) às participantes, no intuito de que as mesmas identificassem os alimentos já ofertados ao filho. Além de permanecer com a gravação, também foi utilizado um roteiro semiestruturado para facilitar o registro destes dados. Essa fase da coleta serviu como apoio para provocar, nas participantes, suas lembranças sobre determinado evento ou período, além de possibilitar o relato de consumo de alimentos considerados supérfluos que, possivelmente por este motivo, eram omitidos nas entrevistas.

Os depoimentos foram categorizados de acordo com a técnica de análise de conteúdo, na modalidade temática ${ }^{(7)}$. Os temas foram interpretados à luz da Teoria das Representações Sociais, por ser capaz de fornecer o referencial interpretativo tanto para tornar as representações visíveis, quanto para torná-las inteligíveis enquanto formas de prática social ${ }^{(4)}$.

O estudo está inserido em uma pesquisa maior, aprovado pelo Comitê de Ética em Pesquisa da Universidade Federal de Pernambuco, sob o CAAE 0006.0.172.000-09. A participação das mães no estudo ocorreu mediante seu consentimento prévio, através da assinatura do Termo de Consentimento Livre e Esclarecido, bem como do seu responsável, no caso dela ser menor de 18 anos de idade ou não emancipada. Visando garantir o anonimato, foram atribuídos nomes fictícios às participantes.

\section{RESULTADOS}

A idade das mães variou de 14 a 19 anos, sendo que seis viviam com o companheiro. A renda familiar estava compreendida desde menos de um salário mínimo até dois salários mínimos e nenhuma trabalhava fora do domicílio. Considerando a escolaridade, uma adolescente não era alfabetizada, seis tinham ensino fundamental incompleto e apenas quatro estavam estudando. Quanto ao número de filhos, sete eram primíparas, duas tinham dois filhos e uma, três filhos. Entre as crianças, a idade esteve compreendida entre sete e 11 meses, sendo que oito ainda recebiam leite materno.

A partir dos discursos das adolescentes, foram identificadas quatro categorias temáticas: conflito do amamentar versus 
consagração do mingau; estabelecendo a alimentação complementar do filho; discurso cristalizado: "danoninho vale mais que um bifinho"; a (in)definição dos hábitos alimentares maternos: implicações para a alimentação infantil.

\section{Temática 1: Conflito do amamentar versus consagração do mingau}

Os discursos revelaram que a prática do aleitamento materno mostra-se controversa e conflituosa. Embora a amamentação seja iniciada, o que estas mulheres almejam é a instituição do aleitamento artificial, representado pelo mingau. $\mathrm{O}$ que parece influenciar a oferta do leite materno é seu caráter protetor de doenças:

Com o leite (materno) ela está mais protegida. (Thaísa)

Leite de peito evita doenças. (Carina)

Os relatos de incômodo advindos da prática do aleitamento materno, todavia, parecem superar qualquer qualidade que o leite materno possa apresentar:

Não posso sair um minuto por causa do peito. (Carina)

A gente não dorme direito, é um horror. (Patrícia)

Chorava direto, eu já não aguentava mais. (Virgínia)

Percebe-se que embora a amamentação seja iniciada, e muitas vezes mantida, diante das dificuldades as adolescentes buscam o que lhes é familiar e invocam o leite artificial. O mingau passa a ser retratado em sua imponência, como a solução para os problemas que o leite materno não consegue sanar:

Quando deu o leite ela dormiu, parou de chorar. (Daniele) Para ele dormir mais noite tranquila. (Flávia)

Tive que dar mingau para ele não ficar com fome. (Vanessa) O mingau dela é sagrado. (Patrícia)

A consagração do mingau, citada nas falas, revela que sua representação social ainda é muito forte em nossa sociedade. Apesar de reconhecerem as recomendações de aleitamento materno exclusivo até o sexto mês, o que estas adolescentes enfatizam nesse período não é necessariamente o início da alimentação complementar, mas do aleitamento artificial:

Eu dei até os seis meses, para ver se ele pegava mamadeira depois de seis meses. Quem disse que ele pegou? (Rita)

No caso de Flávia, tentou-se superar o "risco" de recusa da criança ao leite artificial ao oferecê-lo precocemente. Para ela, a "fase do mingau" parece ser mais importante do que qualquer benefício do leite materno nos primeiros meses de vida:

A primeira alimentação, eu dei o mingau, para ele não se acostumar só no peito, porque depois que tivesse nessa fase de tomar o mingau ele não ia querer. (Flávia)

Para as que não conseguem estabelecer o aleitamento artificial, segue o desespero e o desapontamento:
Dei em uma seringa e ele botou para fora. Todo mundo pega mamadeira, menos esse menino! (Rita)

Fico tentando dar mingau, mas ele não aceitou de jeito nenhum. (Luana)

\section{Temática 2: Estabelecendo a alimentação complementar do filho}

Ao escolher os alimentos que irão compor o cardápio dos fiIhos, frequentemente as mulheres fazem associação com a saúde das crianças, selecionando os alimentos que julgam ser "fortes":

Eu gosto de fazer mingau com inhame, que é forte. (Patrícia) Feijão é forte, para não dar anemia. (Rita)

Feijão, inhame, macaxeira, verduras, frutas, pirão, são coisas fortes, que fazem bem para o corpo dela. (Virgínia)

Entretanto, eventualmente o caráter "forte" de um alimento é entendido como prejudicial, e o mesmo passa a ser representado sob o simbolismo da "comida pesada":

Tenho vontade de dar macaxeira (aipim, mandioca), mas vovó diz que é muito pesado. (Rita)

Um feijãozinho à noite eu não dou a ele, é muito pesado. (Luana)

Tenho medo de dar macaxeira, ficar com a barriga inchada, que é de noite. (Daniele)

A associação da comida pesada com o horário do jantar é, possivelmente, um dos fatores que desencorajam a oferta da segunda refeição de sal, sendo tal refeição substituída pelo mingau:

Quando é três horas (da tarde), eu dou Danone, faço um mingau. E antes dele dormir eu faço mais um mingau. (Flávia)

Umas cinco da tarde eu dou um danoninho, aí depois eu começo a dar mingau novamente. (Vanessa)

Por possuir uma linguagem tradicionalmente técnica, alguns profissionais podem estar desconsiderando em suas orientações conceitos básicos e de forma prática, de preparo do alimento, principalmente para a mãe adolescente, contribuindo para as frequentes inadequações da dieta da criança.

Comecei dar macarrão, carne, tudo no liquidificador. (Mônica)

Botava tudinho no liquidificador, botava na mamadeira, ele comia tudinho. (Flávia)

A representação do alimento liquidificado é uma realidade que se traduz numa prática comum e imprescindível para que a criança não engasgue, além de ser considerado como 
sendo mais fácil de ofertar, frequentemente em mamadeira, tanto para a criança quanto para a mãe adolescente, conforme justificativas:

Eu passo no liquidificador porque ele só tem dois dentinhos, é mais fácil para ele engolir. (Mônica)

Para ele não se engasgar, eu passava no liquidificador. Ficava mais fácil dele comer. (Luana)

Na mamadeira ele comia de uma vez só. Era mais fácil. (Vanessa)

O período de transição da dieta é uma fase crítica no estabelecimento dos hábitos alimentares da criança, que exige disponibilidade e paciência para que seja bem sucedido, como relata Vanessa:

Quando comecei a dar comida no pratinho, era meio difícil porque ele não parava quieto, se melava todo, não tinha paciência. (Vanessa)

É importante que, durante a socialização e o aprendizado alimentar, a criança seja estimulada a perceber os alimentos valendo-se de todos os seus sentidos, não só pelo seu aroma e sabor, mas também pela visualização e manipulação de sua comida. A tendência natural da criança de se interessar e querer pegar o alimento, no entanto, não parece ser bem aceita pelas adolescentes estudadas:

Dou comidinha a ele deitado. Tem que dar deitado. Se for sentado, ele quer brincar, quer se levantar, fica querendo pegar no prato, porque ele é muito inquieto. Muito agoniado. (Carina)

\section{Temática 3: Discurso cristalizado: “danoninho vale mais} que um bifinho"

Há mais de 20 anos, uma propaganda veiculada na mídia clamava "Danoninho vale por um bifinho", deixando implícita a ideia de que o produto não apenas fazia bem à saúde, com o valor nutritivo de um pequeno bife, mas deveria ser parte do cardápio alimentar cotidiano da criança. Essa propaganda foi proibida, mas não a tempo de evitar que tal mensagem se ancorasse à alimentação infantil e se cristalizasse no imaginário social.

\section{É uma coisa normal. Toda criança gosta. (Virgínia)}

O que ele costuma mais comer é feijão, arroz e carne, e o Danone. (Flávia)

Conhecer os riscos do consumo no primeiro ano de vida, contudo, não impede que as mães o ofertem:

Com cinco meses eu já estava dando Danoninho a ele. Dei, vi que ele não tinha tido problema, aí continuei dar danoninho. (Carina)
Carina parece testar a oferta e, com satisfação, comprovar que ele não fez mal ao seu filho. As contradições que afloram nas falas parecem demonstrar um processo de resistência à mudança de suas representações:

Se eu pudesse, eu daria todo dia, porque é bom mesmo, é gostoso. Não como alimentação, mas para enganar o estômago. (Patrícia)

Só para quebrar galho até o almoço, porque não é forte. (Carina)

O produto é representado ora como um alimento saudável e gostoso ora como um paliativo à refeição principal, mas nem por isso dispensável. Mesmo diante da recusa dos filhos, as adolescentes insistem em ofertá-lo:

Eu tento dar um danoninho, mas só que ele não come, não quer. (Vanessa)

Eu dava o danoninho na colher, mas ele não queria, aí eu dava na seringa. (Rita)

É inegável, ainda, o valor simbólico de status que o danoninho confere. Mesmo ante a restrição financeira, as adolescentes fazem verdadeiros sacrifícios para não deixar de ofertá-lo:

De primeiro quem comia Danone era eu, hoje em dia são eles (filhos). Quando eu compro uma bandeja, um dia eu dou, outro dia eu não dou. (Patrícia)

Tem Danones que são bons, porém são também caros, eu não posso comprar. Então a gente compra o básico, o normalzinho. (Thaísa)

Temática 4: A (in)definição dos hábitos alimentares maternos: implicações para a alimentação infantil

O adolescente vivencia intensos processos de mudanças e redefinição, e a alimentação não escapa a essa fase, já que tende a rejeitar os hábitos alimentares da família e a adotar os hábitos do seu grupo de convivência, comumente consumidores de alimentos "da moda".

(Gosto de) Chocolate, biscoito, pizza, cachorro-quente ... (Rita)

A maioria das vezes tomo refrigerante, já virou rotina. Eu não como muita coisa saudável, é pastel, coxinha, essas coisas. (Vanessa)

É difícil eu comer fruta, eu não como nenhum tipo de verdura. (Thaísa)

A valorização e o alto consumo da chamada junk food ("comida lixo") pelas adolescentes estudadas, em detrimento dos alimentos naturais e mais saudáveis, acaba por interferir na escolha e oferta dos alimentos para o filho: 
Chocolate quem mais comeu foi ela! Já dei sorvete, Danone, guaraná... tudo! (Patrícia)

Tudo que eu como eu dou a ela também. Quando eu como biscoito, eu dou a ela. (Daniele)

Picolé, essas coisas assim, eu dou quando eu estou comendo. (Vanessa)

O pirulito eu dou à tardezinha, assim, quando está perto do banho dele. Sei que não é bom, mas quando a gente está comendo o menino fica chorando! (Carina)

Percebe-se nas falas que, comumente, esse tipo de alimento é ofertado à criança durante o consumo pela mãe. É pouco provável, pois, que mães com hábitos alimentares inapropriados estabeleçam uma alimentação infantil adequada. A fala de Carina sugere o quanto a linguagem materna pode influenciar o comportamento alimentar do filho, ao transferir para a criança a sua opinião, negativa, sobre as verduras:

Verdura, tem dia que ele come, tem dia que não, porque enjoa também, não é? Querendo ou não, verdura é bom, mas não tem gosto. (Carina)

\section{DISCUSSÃO}

Diante das vicissitudes da amamentação, as mães adolescentes buscam no mingau o que lhes é familiar e seguro, já que o aleitamento materno é representado como uma ameaça ao sentido de ordem e sensação de controle sobre a criança. As versões contraditórias que emergiram das falas são indicadores da incorporação do discurso técnico, difundido principalmente pelos profissionais da saúde e pela mídia que, apesar de influenciar a representação, ainda não é suficiente para conduzir ao sucesso da amamentação ${ }^{(8)}$.

O saber científico divulga a superioridade do leite materno tradicionalmente com objetividade. O senso comum, entretanto, baseia-se nas práticas interativas do dia a dia, que produzem as representações sociais, fundadas na tradição de um grupo, dentro de uma lógica diferente ${ }^{(9)}$. Neste caso, o desafio da ciência é transpor a prática do aleitamento materno para o dia a dia, com a aflição e a sensação de impotência de muitas vezes não se conseguir dominar e solucionar as dificuldades reais enfrentadas pela mulher que amamenta.

Adotar o aleitamento materno como opção ideal para a alimentação da criança nos primeiros meses de vida, segundo os depoimentos analisados, implica em superar obstáculos, como abdicar horas de sono e lazer, percebidos como dificultadores do aleitamento materno exclusivo.

Para a escolha, preparo e oferta dos alimentos, as adolescentes ressignificam as orientações dos profissionais e seguem uma lógica própria que, não raro, está em desacordo com o ideal. As representações dos alimentos são comumente ancoradas em representações mais arcaicas, onde o caráter "forte" de um alimento pode estar associado tanto com o "bom" - porque protege o organismo de doenças - quanto com o "perigoso" - porque sua força pode "sobrecarregar" o organismo ${ }^{(10)}$. Neste caso, o alimento é representado sob o simbolismo da "comida pesada".

A análise dos depoimentos permitiu identificar que o temor em oferecer uma "comida pesada" é particularmente associado ao período noturno, o que pode justificar a ausência da segunda refeição de sal na dieta dos filhos. Estudo quantitativo ${ }^{(11)}$ evidenciou a ausência dessa refeição como a principal inadequação da dieta das crianças, e constatou-se, assim como no presente estudo, que no horário do jantar tal refeição é substituída pelo mingau.

O preparo da comida liquidificada, por sua vez, está entranhada pelo simbolismo do medo do engasgo. Não obstante, os alimentos devem ser oferecidos amassados com garfo e, progressivamente, em pedaços, nunca liquidificados ou peneirados. A oferta de uma dieta liquidificada, além de não atingir a densidade energética necessária, prejudica o processo de desenvolvimento da mastigação ${ }^{(12-14)}$.

Em um estudo de tendências temporais, que avaliou o padrão da alimentação complementar de crianças menores de um ano de idade de 1998 a 2008, verificou-se uma tendência de queda significativa na proporção de crianças que receberam alimentos com consistência adequada para a sua idade ${ }^{(15)}$. Em contrapartida, existem evidências de que há um período específico para a introdução do alimento com consistência, por volta dos seis a sete meses, e seu atraso pode acarretar problemas diversos de aceitação alimentar, a curto e longo prazo ${ }^{(14)}$.

Além de temer que a criança se engasgue, a oferta dos alimentos liquidificados é referida pelas adolescentes como sendo mais fácil de oferecer. A visível falta de paciência, característica da adolescência, tende a se manter mesmo com a maternidade, e interfere no cuidado da criança ${ }^{(16)}$. Neste caso, além do risco iminente de uma sufocação, a mãe, ao inibir os sentidos visual e táctil da criança, pode, a longo prazo, contribuir negativamente para a aceitação alimentar, formando um "círculo vicioso de impaciência".

As mães adolescentes reinterpretam e reordenam os discursos dos profissionais da saúde a partir do mundo do dia a dia ${ }^{(17)}$. Através desta representação elaborada, não só estabelecem as práticas alimentares do filho como atribuem significados a sua ação, de acordo com sua história de vida e com o conhecimento herdado da interação com os que as cercam.

O alimento vem imbuído em valores simbólicos diversos, muitos resultantes da influência da mídia, que desempenha função relevante na vida cultural de uma sociedade. Neste caso, o queijo petit suisse, o popular danoninho, mostrou-se como o melhor exemplo de uma representação produzida e disseminada pela mídia, onde o que parecia abstrato a uma geração, torna-se familiar e concreto para a seguinte ${ }^{(4)}$.

Os achados do estudo desvelam o quanto esse produto se incorpora à dieta infantil, como se fosse essencial ofertá-lo desde o período de transição da dieta, compondo o leque de alimentos complementares. No entanto, sua oferta é desaconselhada no primeiro ano de vida, principalmente pelo seu poder alergênico. Pesquisa realizada pela Associação Brasileira de Defesa do Consumidor ${ }^{(18)}$ avaliou a qualidade de queijos petit suisse e constatou que todos os produtos tinham açúcar 
em excesso, muito acima do ideal recomendado para o consumo diário em crianças.

Torna-se difícil encaixar novas orientações, já que as condutas alimentares estão incorporadas na interioridade dos sujeitos e encapsuladas pelo aspecto afetivo e pelo prazer que emanam $^{(19)}$. Restringir a oferta do danoninho no primeiro ano de vida nos remete de encontro às representações sociais, ou à produção cultural, de uma comunidade, que tende a resistir a conceitos e atividades que ameaçam destruir sua identida$\mathrm{de}^{(20)}$. Esta resistência torna-se um ruído no processo comunicativo, distorcendo e impedindo que as orientações dos profissionais da saúde sejam transmitidas adequadamente.

Percebe-se que os hábitos de consumo da família, mesmo de alimentos não saudáveis, são transferidos à criança. $\mathrm{O}$ imediatismo e a busca pelo prazer e pela novidade são marcas do comportamento do adolescente, que contribuem para a substituição de alimentos in natura por produtos industrializados e processados, frequentemente mais calóricos e menos nutritivos ${ }^{(21)}$.

Estudos recentes têm associado o comportamento parental alimentar com o comportamento alimentar da criança, sobretudo quando as mães possuem pouca idade. As práticas de alimentação maternas destacam-se como contribuintes importantes para o desenvolvimento da obesidade e hábitos alimentares obesogênicos em crianças pequenas ${ }^{(2,22-23)}$.

Estudo realizado em um município do Rio de Janeiro ${ }^{(24)}$, evidenciou que a alimentação complementar de filhos de adolescentes é similar à de filhos de mulheres adultas. Todavia, o mesmo não investigou o consumo de supérfluos, ao contrário de estudo realizado no sul do país(3), onde se observou que as mães adolescentes ofertam mais refrigerante, café, biscoitos e salgadinhos, com diferença estatisticamente significante quando comparadas às mães adultas.

A oferta desse tipo de alimento é desaconselhada nos primeiros anos de vida, já que pode potencializar o risco de desenvolvimento de obesidade e suas co-morbidades, além do risco de alergias e contaminação ${ }^{(12)}$. O marketing industrial, entretanto, estimula o seu consumo e os meios de comunicação de massa aceleram essa tendência, ao fixar na mente das pessoas representações "superimpostas"(4).
As representações sociais circulam, entrecruzam, dissipam e se cristalizam continuamente em nosso cotidiano, impregnando a maioria dos alimentos que consumimos ${ }^{(4)}$. Compreender, pois, as práticas alimentares como um fenômeno multifacetado implica em uma atuação mais eficaz do profissional da saúde, de modo a possibilitar a modificação e o redirecionamento de sua abordagem para esse grupo singular, oferecendo apoio sensível e especializado ${ }^{(25)}$.

\section{CONCLUSÕES}

O estudo permitiu desvelar as representações sociais de mães adolescentes quanto à alimentação de seus filhos. As representações que conduzem as práticas maternas na escolha, preparo e oferta dos alimentos seguem uma lógica particular, onde as adolescentes reinterpretam os discursos técnicos nos termos da sua cultura. Conhecer as representações das jovens mães e o simbolismo que atribuem a determinado alimento permite maior compreensão das suas atitudes e escolhas, direcionando e facilitando as atividades de Educação em Saúde na promoção de hábitos alimentares saudáveis na infância e, também, na idade adulta.

Aos profissionais, será possível identificar o momento oportuno de se oferecer a orientação alimentar, se possível desde o período pré-natal, desencorajando atitudes não benéficas à saúde da criança e ampliando as representações benéficas plasmadas ao conhecimento popular, de modo a adaptar o discurso técnico e normativo. O importante papel dos profissionais, no entanto, não dispensa a necessidade de políticas públicas de incentivo à alimentação saudável, principalmente com o controle das propagandas de alimentos não saudáveis destinados a crianças e adolescentes.

\section{AGRADECIMENTOS}

Os autores agradecem ao Conselho Nacional de Desenvolvimento Científico e Tecnológico (CNPq) pelo financiamento do Projeto "Representações sociais das práticas alimentares entre adolescentes grávidas de uma comunidade em Recife - PE", que originou a presente pesquisa (processo 475906/2008-0)

\section{REFERÊNCIAS}

1. World Health Organization. Infant and young child feeding [Internet]. Geneva: WHO; 2014 [cited 2013 June 27]. Available from: https://www.nlm.nih.gov/bsd/uniform_requirements.html

2. Rodgers RF, Paxton SJ, Massey R, Campbell KJ, Wertheim $\mathrm{EH}$, Skouteris $\mathrm{H}$, et al. Maternal feeding practices predict weight gain and obesogenic eating behaviors in young children: a prospective study. Int J Behav Nutr Phys Act [Internet]. 2013 [cited 2013 June 27];10(24). Available from: http://www.ncbi.nlm.nih.gov/pubmed/23414332

3. Fuzeto KLR, Oliveira ACL. Comparação da prática do aleitamento materno e da alimentação complementar entre mães adolescentes e adultas, Curitiba/PR. Cad Esc Saúde [Internet]. 2010 [acesso em 25 de outubro de 2014];3:116. Disponível em: http://apps.unibrasil.com.br/revista/ index.php/saude/article/viewFile/334/264

4. Moscovici S. Representações sociais: investigações em psicologia social. 9. ed. Petrópolis: Vozes; 2011.

5. Flick U. Introdução à pesquisa qualitativa. 3. ed. Porto Alegre: Artmed; 2009.

6. Prefeitura do Recife. Plano Municipal de Saúde 20062009 [Internet]. Recife: Prefeitura do Recife; 2005 [acesso em 25 de outubro de 2014]. Disponível em: http://www. recife.pe.gov.br/noticias/arquivos/227.pdf 
7. Bardin L. Análise de conteúdo. Lisboa: Edições 70; 2014.

8. Lima AP, Javorski M. Amamentação interrompida: vivência de mulheres-mães. Rev Enferm UFPE [Internet]. 2010 [acesso em 21 de maio de 2013];4(1):227-35. Disponível em: http://bases.bireme.br/cgi-bin/wxislind.exe/iah/online/ ? lsisScript $=$ iah/iah. $x$ is \&src $=$ google $\&$ base $=$ BDENF\&lang $=$ p\&nextAction $=$ Ink\&exprSearch $=18827$ \&indexSearch $=$ ID

9. Guareschi PA. "Sem dinheiro não há salvação": ancorando o bem e o mal entre os neopentecostais. In: Guareschi PA, Jovchelovitch S, editores. Textos em representações sociais. 13. ed. Petrópolis: Vozes; 2011.

10. Spink MJ. Desvendando as teorias implícitas: uma metodologia de análise das representações sociais. In: Guareschi PA, Jovchelovitch S, editores. Textos em representações sociais. 13. ed. Petrópolis: Vozes; 2011.

11. Santos CS, Lima LS, Javorski M. Fatores que interferem na transição alimentar de crianças entre cinco e oito meses: investigação em serviço de puericultura do Recife, Brasil. Rev Bras Saúde Matern Infant. 2007;7(4):373-80.

12. Ministério da Saúde (BR), Secretaria de Atenção à Saúde, Departamento de Atenção Básica. Saúde da criança: nutrição infantil: aleitamento materno e alimentação complementar [Internet]. Brasília (DF): Ministério da Saúde; 2009 [acesso em 25 de outubro de 2014]. Disponível em: http://bvsms.saude.gov.br/bvs/publicacoes/saude_crianca_nutricao_aleitamento_alimentacao.pdf

13. Flores HS. Importance of infant feeding during the first year of life. Gac Med Mex [Internet]. 2011 [cited 2013 June 27];147 Suppl 1:22-31. Available from: http://www. ncbi.nlm.nih.gov/pubmed/22352125

14. Schwartz C, Scholtens PA, Lalanne A, Weenen H, Nicklaus $\mathrm{S}$. Development of healthy eating habits early in life. Review of recent evidence and selected guidelines. Appetite [Internet]. 2011 [cited 2013 June 27];57(3):796-807. Available from: http://www.ncbi.nlm.nih.gov/pubmed/21651929

15. Oliveira DA, Castro IR, Jaime PC. Complementary feeding patterns in the first year of life in the city of Rio de Janeiro, Brazil: time trends from 1998 to 2008. Cad Saude Publica [Internet]. 2014 [cited 2013 June 27];30(8):1755-64. Available from: http://www.ncbi.nlm.nih.gov/pubmed/25210914
16. Valila MG, Moraes NA, Dalbello NN, Vieira SS, Beretta MIR, Dupas G. Gravidez na adolescência: conhecendo a experiência da família. REME Rev Min Enferm [Internet]. 2011 [acesso em 25 de outubro de 2014];15(4):556-66. Disponível em: http://www.reme.org.br/artigo/detalhes/70

17. Minayo MCS. O conceito de representações sociais dentro da sociologia clássica. In: Guareschi PA, Jovchelovitch $\mathrm{S}$, editores. Textos em representações sociais. 13. ed. Petrópolis: Vozes; 2011.

18. Queijos petit suisse: infância adocicada. Rev Pro Teste. 2007;5(61):8-12.

19. Romanelli G. O significado da alimentação na família: uma visão antropológica. Medicina (Ribeirão Preto). 2006;39(3):333-9.

20. Bauer M. A popularização da ciência como imunização cultural: a função de resistência das representações sociais. In: Guareschi PA, Jovchelovitch S, editores. Textos em representações sociais. 13. ed. Petrópolis, Vozes; 2011.

21. Bica I, Cunha M, Costa J, Rodrigues V, Santos MR, Monteiro J. Hábitos alimentares na adolescência: implicações no estado de saúde. Millenium [Internet]. 2012 [acesso em 25 de outubro de 2014];42:85-103. Disponível em: http://repositorio.ipv.pt/bitstream/10400.19/1201/1/ h\%C3\%A1bitos\%20alimentares.pdf

22. Betoko A, Charles MA, Hankard R, Forhan A, Bonet M, Saurel-Cubizolles $M J$, et al. Infant feeding patterns over the first year of life: influence of family characteristics. Eur J Clin Nutr [Internet]. 2013 [cited 2013 June 27];67(6):631-7. Available from: http://www.ncbi.nlm.nih.gov/pubmed/23299715

23. Liu $\mathrm{HH}$, Chen JJ. Effect of parental feeding behavior on eating behavior of children aged 1-3 years. Zhongguo Dang Dai Er Ke Za Zhi [Internet]. 2014 [cited 2013 June 27];16(6):643-7. Available from: http://www.ncbi.nlm. nih.gov/pubmed/24927444

24. Cruz MCC, Almeida JAG, Engstrom EM. Práticas alimentares no primeiro ano de vida de filhos de adolescentes. Rev Nutr. 2010;23(2):201-10.

25. Lima APE, Javorski M, Vasconcelos MGL. Práticas alimentares no primeiro ano de vida. Rev Bras Enferm. 2011;64(5):912-8. 